\title{
Study on the R\&D Pattern of Shipping Industry Cluster Network From the perspective of Coopetition-relationships between Enterprises
}

\author{
Jinlou Zhao and Gang Ge \\ School of Economics and Management, Harbin Engineering University \\ luciferyao@126.com
}

\begin{abstract}
In recent years, shipping industry clusters in our country present network development trend, and there are complex coopetition-relationships between enterprises in this cluster network. This fact brings the research about the $R \& D$ pattern of shipping industry clusters a new challenge. From the perspective of coopetition-relationships between enterprises, we firstly build the multi-level coopetition model of the shipping industry cluster network, and then use the Lotka-Volterra model and the Evolution Game model to synthetically simulation analyze coopetition-relationships between enterprises in this network and the interaction relationship between the coopetition-relationships and the $R \& D$ pattern, and finally put forward the countermeasures and suggestions about how to improve the $R \& D$ pattern of the shipping industry cluster network in our country.
\end{abstract}

Keywords: shipbuilding industry cluster network; coopetition; R\&D pattern; simulation analyze

\section{Introduction}

In recent years, Chinese shipbuilding industry cluster is booming, its international status is rising, and its production is among the best in the world market. But our shipping productions are mainly concentrated in the low-tech ship manufacturing, and there is a high cost of manufacturing, excess production capacity and other issues, while the production capacity of high-tech ship manufacturing is very short[1]. Therefore, how to complete the transformation from "big" to "strong" is the key problem of the development of Chinese shipbuilding industry. To realize it, the key to solve this problem is to adopt a reasonable $R \& D$ pattern and furtherly improve the R\&D ability of Chinese shipbuilding industry cluster [2]. Comas (2012) come to conclusion that the research focus of early literature about the shipping development are mainly from the perspective of the individual level and industry chain level and also so its countermeasures about how to improve R\&D ability[3]. However, the cluster structure of shipbuilding industry in China has changed from a simple chain structure into a network structure with complex features [4]. This new situation has put forward a new research task for entrepreneurs and researchers, that is to study the structure and operating mechanism of the ship industry cluster, and then select the feasible R\&D pattern. The existing research shows that the structure of the shipbuilding industry cluster network is determined by the partnership and competitive relationship between the network members. At the same time, it plays an important role in the R\&D pattern of this cluster network, and is also the fundamental factor to determine whether the network has the advantage of international competition [5].

Therefore, this paper analyzes the structural features of the shipping industry cluster network from the perspective of the coopetition-relationships between enterprises, studys the evolution law of the network, and explores the factors that affect R\&D pattern of this network, in order to put forward the R\&D pattern which 
fitting Chinese shipping industry cluster network. Firstly, this paper constructs the multi-level competition model of shipping industry cluster network by combing relevant literatures, Secondly, analyzes the coopetition-relationships between enterprises at different level based the Lotka-Volterra model and evolutionary game model, and then constructs the LV-EG model, Finally, Simulationly studys the changes of coopetition-relationships between enterprises along with the evolution of the shipping industry cluster network and how it impact on the R\&D pattern, in order to explore the main factors that can improve the R\&D ability of this network.

\section{Theory and Model}

\subsection{Theory}

A large number of studies show that the ship is a large complex product, and the shipping industry cluster has the characteristics of CoPS (complex product system) and network characteristics [6-8]. We believe that the shipping industry cluster network is the sum of the partnerships between enterprises which involved in the design and production activities. In the shipping industry cluster network, Ship production and R\&D activities are based on the shipyard as the core, and others including all SESs (supporting enterprises and suppliers) who provide key technologies and components. This shows that the ship industry cluster network presents a nuclear structure with the core enterprise of the shipyard, and has the characteristic of scale free and small world [3-8]. Choi and Kim(2010) point out that a cluster network with small world characteristics can contribute to the diffusion of knowledge and technology, and the small world effect has an important influence on the R\&D ability of the network [9]. In addition, in the shipping industry cluster network, it's a fact that many core enterprises (shipyard) which are facing the same market competing for more orders, and then the cluster network has the features multi alliance structure and there are competition relationships between SESs which is seeking the partnership with shipyard just because of this fact[8-10]. Norback(2014). Believes that the benign competition can stimulate the network member enterprises to carry out independent research and development, while the price war based vicious competition is not conducive to the development of the network [11]. In summary, there is a relationship between different levels of cooperation and competition within the shipping industry cluster network, which has an important influence on the development of the network.

Based on the above viewpoints, this paper firstly constructs the multi-level competition model of the ship industry cluster network (as shown in Figure 1) as the basic research frame of the shipping industry cluster network R\&D ability. In the shipbuilding industry cluster network, there is a competitive relationship between the shipyards which is facing the same market (such as $\mathrm{M}_{1}$ and $\mathrm{M}_{2}$ ). In addition, there is a competitive relationship and patternship between the SESs in the cluster network (such as $\mathrm{N}_{1}$ and $\mathrm{N}_{2}$, such as $\mathrm{N}_{3}$ and $\mathrm{N}_{4}$ ). In the cluster network, a large number of SESs are connected with the chain operation mode, and they are not directly facing the ship market, the survival and development of the enterprises are mainly relied on the shipyards. 


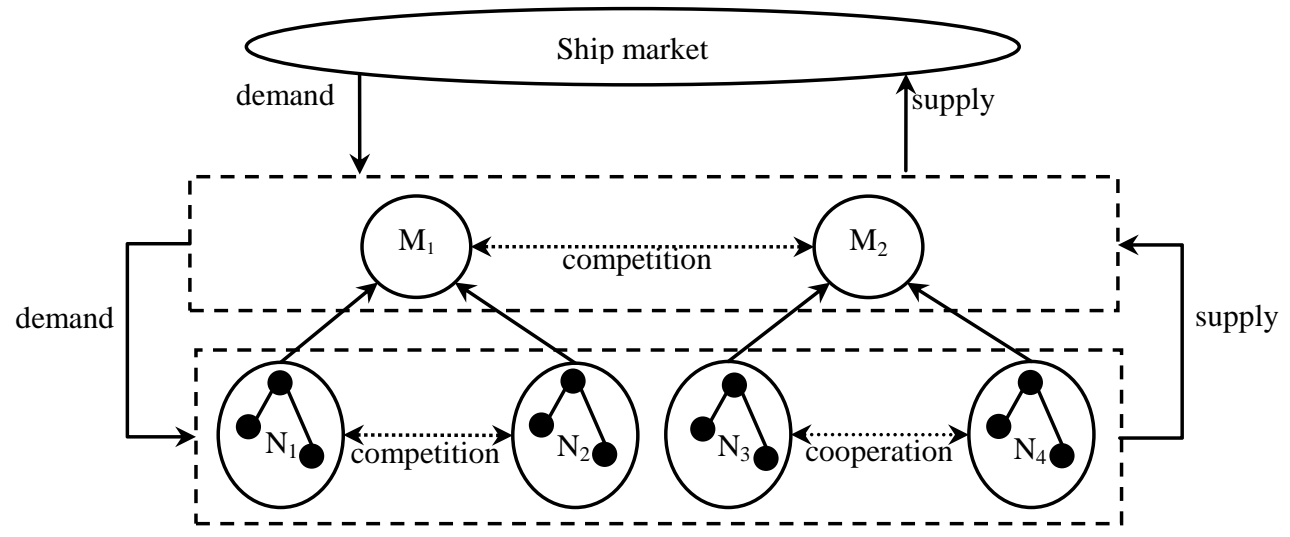

Figure 1. The Multi-Level Coopetition of the Shipping Industry Cluster Network

\subsection{Lotka-Volterra Model}

In recent years, Lotka-Volterra model has been widely used in the field of management research. It can reveal the internal operating mechanism of the formation and evolution of the competition among enterprises, and solve the problem of real management from the perspective of ecology. Such as $\mathrm{Xu}(2008)$ uses this model to study the relationship between product competition and cooperation innovation in communication industry, which provides a new way for the development of communication industry [12], and Chen(2012) also uses this model to simulation research on the evolution path of the photovoltaic industry ecosystem, and analyzes the impact of the competition mechanism on the evolution path of the system, puts forward the operation mode which is suitable for the development of the photovoltaic industry[13]. Obviously, the Lotka-Volterra model can clearly describe the inherent law of enterprise competition. In view of this, inheriting the views of scholars, to product competition as the breakthrough point, we research on the competition relationship and R\&D pattern between shipyards.

In order to facilitate the follow-up study, we assume that there are only two shipyards in the shipping industry cluster network. Competition results between shipyard $M_{1}$ and shipyard $M_{2}$ which are facing the same market can be described as the number of product $p_{1}$ and the number of product $p_{2}$ which is the same as the number of shipowners $P_{1}(t)$ and the number of shipowners $P_{2}(t)$, in other words, the number of product $p_{1}$ can be expressed by $P_{1}(t)$ and the number of product $p_{2}$ can be expressed by $P_{2}(t)$. Based on this, we construct the Lotka-Volterra model of the competition relationship between shipyards in the shipbuilding industry cluster network:

$$
\begin{aligned}
& \frac{\mathrm{d} P_{1}(t)}{d t}=r_{1} \cdot P_{1}(t) \frac{\left[K_{1}-P_{1}(t)-\alpha_{21} P_{2}(t)\right]}{K_{1}} \\
& \frac{\mathrm{d} P_{2}(t)}{d t}=r_{2} \cdot P_{2}(t) \frac{\left[K_{2}-P_{2}(t)-\alpha_{12} P_{2}(t)\right]}{K_{2}}
\end{aligned}
$$

According to the theory of biological populations, two kinds of creatures live by the way of competitive reproduction in the same environment, this process is determined by the following 3 factors. The first factor is its intrinsic growth rate $r_{1}$ and $r_{2}$. In the shipping industry cluster network, the shipyard who is at the top of the supply chain strip off and the key components of the ship production to the SESs, and then assembles and improves the components from them, which means the shipyard's production capacity is determined by the number of SESs. The second factor is restriction effect $K$ of 
environment on biological reproduction. We use $K_{1}$ and $K_{2}$ to represent the largest market capacity of two product groups respectively. The third factor is the inhibition effect $\alpha$ which generated from the competition for resources. As the ship quality is the decisive factor that affects its sales, it is also the concrete manifestation of the ship's R \& $\mathrm{D}$ capability. Thus we use the ship quality to describe the inhibition $\alpha$, in other words, $\alpha_{12}$ is described the inhibition effect of $P_{1}(t)$ on $P_{2}(t)$, and $\alpha_{21}$ is described the inhibition effect of $P_{2}(t)$ on $P_{1}(t)$.

Lotka-Volterra model shows that $P_{2}(t)$ will increase when $P_{1}(t)$ is decreasing. We discover the equilibrium state of competition between $P_{1}(t)$ and $P_{2}(t)$ by analyzing their isoclinic lines. If there is formula that $\mathrm{d} P_{1}(t) / d t=\mathrm{d} P_{2}(t) / d t=0, P_{1}(t)$ 's soclinic line is like the formula $P_{1}(t)+\alpha_{21} P_{2}(t)=K_{1}$ and $P_{2}(t)$ 's soclinic line is like the formula $P_{2}(t)+\alpha_{12} P_{1}(t)=K_{2}$, the number of production will increase when it is below the isoclinic line, and the number of production will decrease when it is above the isoclinic line. Because values of the variables $\left(K_{1}, K_{2}, \alpha_{12}, \alpha_{21}\right)$ is different, there are 4 different kinds of competition results(Figure 2).
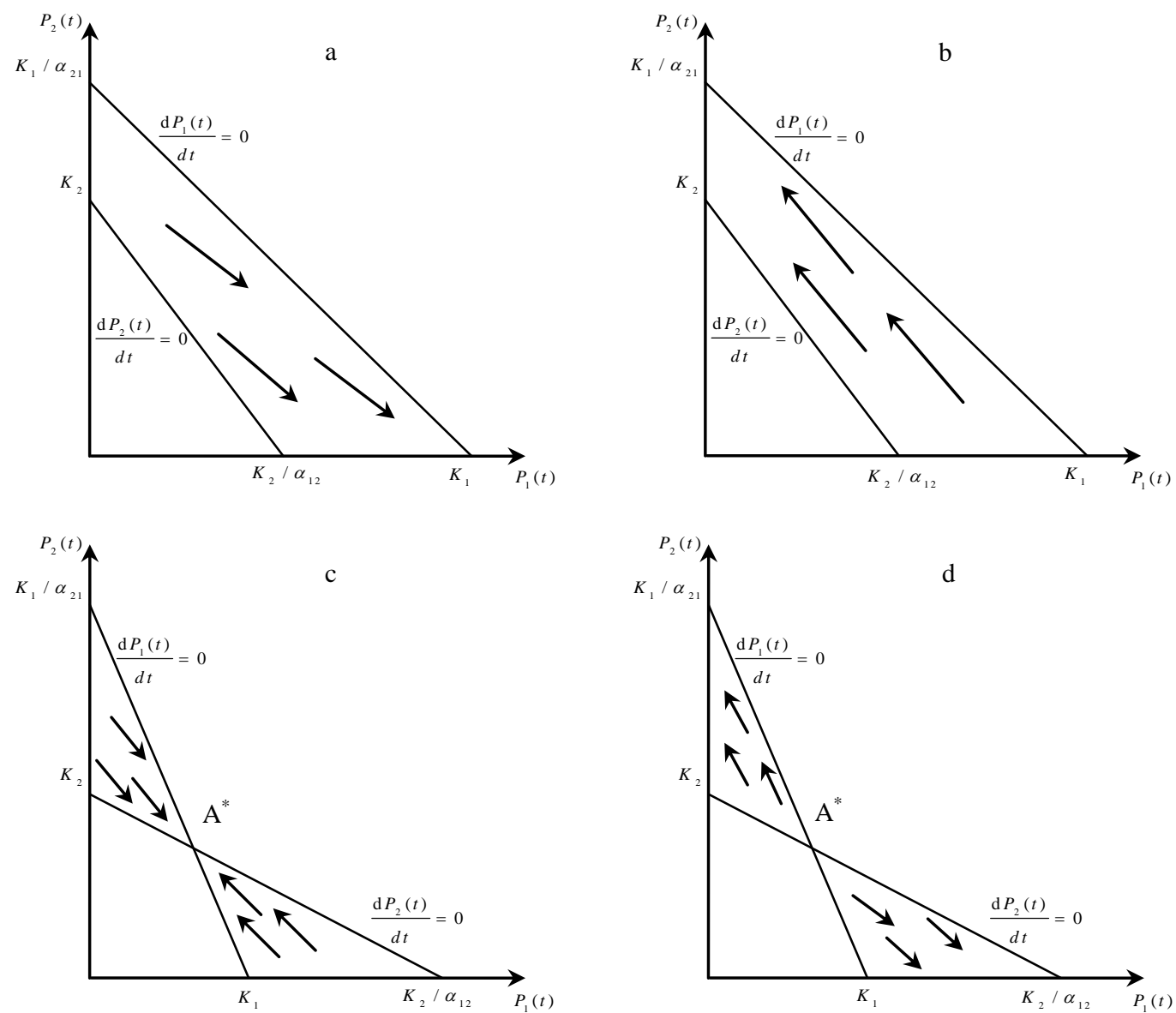

Figure 2. Four Different Kinds of Competition Results

(1) If $K_{1}>K_{2} / \alpha_{12}$ and $K_{2}<K_{1} / \alpha_{21}$, then $P_{1}(t)$ wins (Figure 2a).

(2) If $K_{1}<K_{2} / \alpha_{12}$ and $K_{2}>K_{1} / \alpha_{21}$, then $P_{2}(t)$ wins (Figure 2b).

(3) If $K_{1}<K_{2} / \alpha_{12}$ and $K_{2}<K_{1} / \alpha_{21}$, then $P_{1}(t)$ 's isoclinic line and $P_{2}(t)$ 's isoclinic line intersect at the point $\mathrm{A}$. The result is they can coexist. 
(4) If $K_{1}>K_{2} / \alpha_{12}$ and $K_{2}>K_{1} / \alpha_{21}$, then $P_{1}(t)$ 's isoclinic line and $P_{2}(t)$ 's isoclinic line intersect at the point $\mathrm{A}^{*}$. The result that which can win is not sure.

\subsection{Evolution Game Model}

In the shipping industry cluster network, there are not only the competition relationships between shipyards, but also the coopetition relationship between SESs. In the process of the development of the cluster network, the SES has the option to change the existing cooperative relationship, and to establish the cooperative relationship with the shipyard which is more beneficial to itself. In this situation, SESs need to make a decision and choice at a second time. But limited to their own ability and cooperation lock effect, the SESs only have two kinds of different behaviors which cooperate with $M_{1}$ or $M_{2}$. This problem can be solved by the game theory.

The core concept of evolutionary game model is the 'evolutionary stability strategy' (ESS) and 'replication dynamics'. The ESS of this research indicates that a stable state that the group that SESs choose to cooperate with $m_{1}$ resists the strategy(which choose to cooperate with $\mathrm{M}_{2}$ ). The ESS a strategy $c^{*}$ that Condition 1 (there is a strategy $c^{*}$ whenever if $u\left(c^{*}, c^{*}\right) \geq u\left(c^{*}, c\right)$ ) and Condition 2 (If $c^{*} \neq c$ and $u\left(c^{*}, c^{*}\right)=u\left(c^{*}, c\right)$, then $\left.u\left(c^{*}, c^{*}\right)>u(c, c)\right)$ are set up at the same time. 'Replication dynamics' is a dynamic differential equation describing the frequency of a particular strategy in a population.

We assume that the total number of SESs is $n$, Ratio of them who choose to cooperate with $M_{1}$ is $x \in[0,1]$ and Ratio of them who choose to cooperate with $M_{2}$ is $1-x$. For any two $\operatorname{SESs}\left(N_{1}\right.$ and $\left.N_{2}\right)$, there is a strategy c. According to this, we construct the payment matrix of the SESs:

Table 1. The Payment Matrix of the SESs

\begin{tabular}{c|c|c}
\hline & $M_{1}$ & $M_{2}$ \\
\hline$M_{1}$ & $Q_{1}+\left(1-\varphi_{1}\right) T-\varphi_{1} S, Q_{1}+\left(1-\varphi_{1}\right) T-\varphi_{1} S$ & $Q_{1}, Q_{2}$ \\
\hline \multirow{2}{*}{$M_{2}$} & $Q_{2}, Q_{1}$ & $Q_{2}+\left(1-\varphi_{2}\right) T-\varphi_{2} S$, \\
& & $Q_{2}+\left(1-\varphi_{2}\right) T-\varphi_{2} S$ \\
\hline
\end{tabular}

In the payment matrix of the SESs, $Q_{1}$ is the profit that a SES who cooperates with $M_{1}$ gets from $M_{1}$ and $Q_{2}$ is the profit that a SES who cooperates with $M_{2}$ gets from $M_{2} ; \varphi_{1}$ is the Probability of forming a competitive relationship between two SESs who cooperate with $M_{1}$ and $\varphi_{2}$ is the probability of forming a competitive relationship between two SESs who cooperate with $M_{2}\left(0 \leq \varphi_{1} \leq 1,0 \leq \varphi_{2} \leq 1\right), S$ is the loss of SESs under competition, meanwhile, $1-\varphi_{1}$ the probability is of forming a partnership between two SESs who cooperate with $M_{1}$ and $1-\varphi_{2}$ is the probability of forming a partnership between two SESs who cooperate with $M_{2}, \quad T$ is the additional revenue of SESs under cooperation. SESs' expected profit and the average profit of all is described as the following formula:

$$
\begin{aligned}
& R_{1}=x\left[Q_{1}+\left(1-\varphi_{1}\right) T-\varphi_{1} S\right]+(1-x) Q_{1} \\
& R_{2}=x Q_{2}+(1-x)\left[Q_{2}+\left(1-\varphi_{2}\right) T-\varphi_{2} S\right] \\
& R_{a}=x R_{1}+(1-x) R_{2}
\end{aligned}
$$

It's replication dynamic equation: 


$$
f(x)=d x / d t=x(1-x)\left\{\left[\left(2-\varphi_{1}-\varphi_{2}\right) T-\left(\varphi_{1}+\varphi_{2}\right) S\right] x+Q_{1}-Q_{2}-\left(1-\varphi_{2}\right) T+\varphi_{2} S\right\}
$$

There are three stable states about replication dynamics which can be described these formula $x^{*}=0, \quad x^{*}=1$ and $x^{*}=e=\left(Q_{1}-Q_{2}-\left(1-\varphi_{2}\right) T+\varphi_{2} S\right) /\left[\left(2-\varphi_{1}-\varphi_{2}\right) T-\left(\varphi_{1}+\varphi_{2}\right) S\right]$. There is a Requirement in the stability theory of ordinary differential equations: a stable state has to be robust to small perturbations to become an evolutionary stable strategy.

\subsection{LV-EG Model}

Nagurney (2013)considers that the cooperation between the enterprises can affect the quantity and quality of productions in the supply chain network[14]. And then Malecki (2013) considers that the coopetition relationships between the enterprises have a significant positive effect on the R\&D ability of the network. Whether the competition or cooperation will promote technological innovation and enhance production performance and functionality[15]. Then Watts and Gilbert simulation Research on the network that product innovative production, and find that the relationship between downstream enterprises which as suppliers tend to form a competition relationship when ship sales are small, and they mainly use the independent $R \& D$ pattern to enhance product components and then get more orders by increasing the performance of the R\&D input; when the ship sales are large, they use the joint R\&D pattern to establish cooperative relationships to increase production capacity[16]. Based on the above views, we combine the Evolution Game model and the Lotka-Volterra model into the LV-EG model to analyze the mechanism about how coopetition relationships between SESs impact on the competition relationship between shipyards.

Based on the views of Watts and Gilbert(2014)[16], we firstly establish a contact between $\alpha$ and $\varphi$. When there are competition relationship s between SESs, they focus on R\&D investment and component innovation, in order to enhance the competitiveness of the components and then get more profit, which bring this cluster network an additional revenue $\lambda$ coming from competitive R\&D; when there are partnerships between SESs, they are committed to technological innovation to achieve the scale effect and increase the output of the ship production, which bring this cluster network an additional revenue $\lambda^{\prime}$ coming from cooperative R\&D. But due to limitations of SESs' capital, they cannot put all capital on product innovation and process innovation at the same time. Thus, there is function relationship between $\alpha$ and $\varphi$ :

$\alpha_{12}=x\left(\lambda^{\prime}+\lambda \varphi_{1}-\lambda^{\prime} \varphi_{1}\right) \quad ; \quad \alpha_{21}=(1-x)\left(\lambda^{\prime}+\lambda \varphi_{2}-\lambda^{\prime} \varphi_{2}\right)$

In addition, the relationship between SESs is related to the requirements of the ship components of the shipyard, and the demand is positively related to the market share of the products. Thus, there is a positive correlation between SESs' strategy about whether competing or to cooperating with other SES and the market share of the product group and there is a formula like this:

$$
\varphi_{1}=\left\{\begin{array}{c}
P_{2}(t) /\left(P_{1}(t)+P_{2}(t)\right), P_{1}(t) \leq P_{2}(t) \\
1-P_{2}(t) /\left(P_{1}(t)+P_{2}(t)\right), P_{1}(t)>P_{2}(t)
\end{array} \quad ; \varphi_{2}=\left\{\begin{array}{c}
P_{1}(t) /\left(P_{1}(t)+P_{2}(t)\right), P_{1}(t) \geq P_{2}(t) \\
1-P_{1}(t) /\left(P_{1}(t)+P_{2}(t)\right), P_{1}(t)<P_{2}(t)
\end{array}\right.\right.
$$

We secondly establish a contact between $Q$ and $P(t) \cdot Q$ is related to market share of the ship production, the higher the market share of the product group, the greater the demand of the ship components, the more SESs earn.

$$
Q_{1}=q_{1} P_{1}(t) /\left[P_{1}(t)+P_{2}(t)\right] ; Q_{2}=q_{2} P_{2}(t) /\left[P_{1}(t)+P_{2}(t)\right]
$$

We thirdly establish a contact between $r_{1}, r_{2} n \varphi_{1}$ and $\varphi_{2}$. As stated above, $r_{1}$ and $r_{2}$ is related to $n$ and SESs are able to increase the number of the ship production by cooperation R\&D pattern. Thus, $\varphi_{1}$ and $\varphi_{2}$ also can have an impact on $r_{1}$ and $r_{2}$. To sum 
up, there are formula that $r_{1}=\theta_{1}\left(3 x-\varphi_{1} x+1\right)$ and $r_{2}=\theta_{2}\left(x-\varphi_{2} x+2\right) \circ$ Among them, $\theta_{1}$ and $\theta_{2}$ is the efficiency how fast the shipyard assemble components supplied by SESs. Because of $P_{1}(t)$ and $P_{2}(t)$ face the same market, there is a formula that $K_{1}=K_{2}=K$. Based on this, we get the LV-EG model as follows,

$$
\begin{aligned}
& \frac{\mathrm{d} P_{1}(t)}{d t}=\theta_{1}\left(3 x-\varphi_{1} x+1\right) \bullet P_{1}(t) \frac{\left[K-P_{1}(t)-(1-x)\left(\lambda+\lambda \varphi_{2}-\lambda^{\prime} \varphi_{2}\right) \bullet P_{2}(t)\right]}{K} \\
& \frac{\mathrm{d} P_{2}(t)}{d t}=\theta_{2}\left(x-\varphi_{2} x+2\right) \bullet P_{2}(t) \frac{\left[K-P_{2}(t)-x\left(\lambda+\lambda \varphi_{1}-\lambda^{\prime} \varphi_{1}\right) \bullet P_{1}(t)\right]}{K} \\
& \frac{d x}{d t}=x(1-x)\left\{\left[\left(2-\varphi_{1}-\varphi_{2}\right) T-\left(\varphi_{1}+\varphi_{2}\right) S\right] x+\frac{q_{1} P_{1}(t)-q_{2} P_{2}(t)}{P_{1}(t)+P_{2}(t)}-\left(1-\varphi_{2}\right) T+\varphi_{2} S\right\}
\end{aligned}
$$

formula (12) indicates that there are three equilibrium points including $x^{*}=0, x^{*}=1$ and $x^{*}=e$ if $0<e<1$. Among them, the value of $e$ is:

$$
e=\frac{\left[\left(1-\varphi_{2}\right) T-\varphi_{2} S\right]\left[P_{1}(t)+P_{2}(t)\right]-q_{1} P_{1}(t)+q_{2} P_{2}(t)}{\left[\left(2-\varphi_{1}-\varphi_{2}\right) T-\left(\varphi_{1}+\varphi_{2}\right) S\right]\left[P_{1}(t)+P_{2}(t)\right]}
$$

In order to further analyze the stability of the equilibrium points and the competition under the condition of stability, we use the local stability analysis of the Jacobian matrix to determine the stability of the equilibrium point of the ordinary differential equation [17], and the Jacobian matrix is:

$J=\left\{\begin{array}{ccc}r_{1}\left[K-2 P_{1}(t)-\alpha_{21} P_{2}(t)\right] / K & -r_{1} \alpha_{21} P_{1}(t) / K & 0 \\ -r_{2} \alpha_{12} P_{2}(t) / K & r_{2}\left[K-2 P_{2}(t)-\alpha_{12} P_{1}(t)\right] / K & 0 \\ 0 & 0 & (a x+b)(1-2 x)+a x(1-x)\end{array}\right]$

The determinant of the Jacobian matrix is:

DetJ $=\left\{\left[r_{1}\left(K-2 P_{1}(t)-a_{21} P_{2}(t)\right)\right]\left[r_{2}\left(K-2 P_{2}(t)-\alpha_{12} P_{1}(t)\right]+r_{1} r_{2} \alpha_{21} \alpha_{12} P_{1}(t) P_{2}(t)\right\}[(a x+b)(1-2 x)+a x(1-x)] / K^{2}\right.$

The trace of the Jacobian matrix is:

$T r J=r_{1}\left(K-2 P_{1}(t)-\alpha_{21} P_{2}(t)\right) / K+r_{2}\left(K-2 P_{2}(t)-\alpha_{12} P_{1}(t)\right) / K+(a x+b)(1-2 x)+a x(1-x)$

We come to a conclusion about the stability of the competition results by analyzing The value of determinant and trace of the Jacobian matrix (Tab.2).

Table 2. The Competition Results

\begin{tabular}{c|c|c|c|c|c}
\hline $\begin{array}{c}\text { equilibrium } \\
\text { point } x\end{array}$ & Situation & DetJ & $T r J$ & results & Condition \\
\hline \multirow{4}{*}{$x=0$} & $P_{1}(t)$ wins & + & + & Instable & instable under any conditions \\
\cline { 2 - 6 } & $P_{2}(t)$ wins & + & - & $E S S$ & $q_{2}-q_{1}>T-S, \lambda^{\prime} \theta_{1}-4 \lambda \theta_{2}<\left(q_{2}-q_{1}+T-S\right) / K$ \\
\cline { 2 - 6 } & Coexistence & - & - & Instable & instable under any conditions \\
\hline \multirow{4}{*}{$x=1$} & $P_{1}(t)$ wins & + & - & $E S S$ & $q_{1}-q_{2}>T-S, \lambda^{\prime} \theta_{2}-4 \lambda \theta_{1}<\left(q_{1}-q_{2}+T-S\right) / K$ \\
\cline { 2 - 6 } & $P_{2}(t)$ wins & + & + & Instable & instable under any conditions \\
\cline { 2 - 6 } & Coexistence & - & - & Instable & instable under any conditions \\
\hline \multirow{5}{*}{$x=e$} & $P_{1}(t)$ wins & + & + & Instable & instable under any conditions \\
\cline { 2 - 6 } & $P_{2}(t)$ wins & - & - & Instable & instable under any conditions \\
\cline { 2 - 6 } & Coexistence & + & - & $E S S$ & $q_{1}-q_{2}=T-S, \lambda^{\prime} \theta_{2}-4 \lambda \theta_{1}=\left(q_{1}-q_{2}+T-S\right) / K$ \\
\hline
\end{tabular}




\section{Simulation and Numerical Analysis}

In this paper, we use Matlab to simulate the LV-EG model, and analyze how shipyards act to attract more subordinate enterprises in different situations to gain competitive advantage. We firstly assignment the related parameters which is not important for this paper $\left(K=100, P_{1}(0)=8, P_{2}(0)=8, T=40, S=20, \lambda=1, \lambda^{\prime}=0.5\right)$ and analyze the different situation under different values of $q$ and $\theta$.

\section{Situation 1: $\mathbf{M}_{2}$ wins}

If $q_{2}-q_{1}>T-S, \lambda^{\prime} \theta_{1}-4 \lambda \theta_{2}<\left(q_{2}-q_{1}+T-S\right) / K, x=0$ is the evolutionary stability strategy and $P_{2}(t)$ wins. To verify the situation, we assignment the related parameters $q_{2}=90, q_{1}=30, \theta_{2}=2, \theta_{1}=1$ and then use Matlab to simulate the LV-EG model under three different situation of $x=0.3, x=0.6$ and $x=0.9$, the results are as follows:

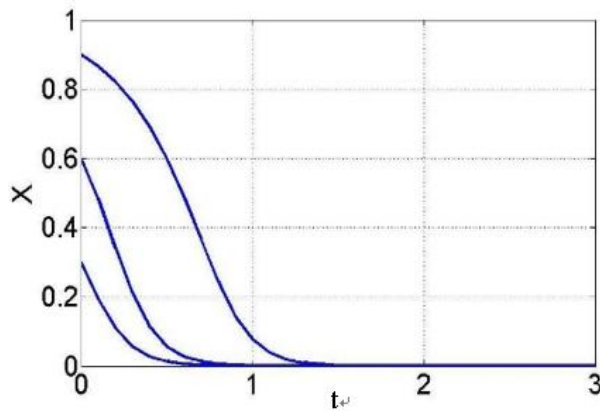

(a) $x$ Evolutionary Trend

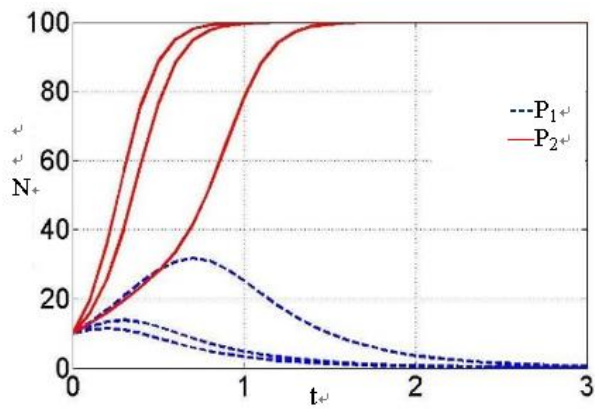

(c) Competition Results

Figure 3. Simulation Results Under $q_{2}=90, q_{1}=30, \theta_{2}=2, \theta_{1}=1$

Figure 3 shows that regardless of the initial state of $x, M_{2}$ can attract all SESs in the cluster network by its own R\&D capability and collaborative R\&D capability, and wins. In the process of long-term competition between $P_{1}(t)$ and $P_{2}(t)$, the number of $P_{1}(t)$ are always lager than $P_{2}(t)$ 's. Therefore, SESs belonging to $M_{2}$ tend to form a cooperative relationship, forming a sub network by adopting joint $R \& D$ pattern, focusing on technological innovation, to form the formation of scale effects to meet the needs of the ship market. In contrast, SESs belonging to $M_{1}$ tend to form a competitive relationship to improve their $R \& D$ ability. However, they are unable to gather funds to achieve sustainable development activities, and over time, have to cooperate with $M_{2}$. Finally, the shipping industry cluster network tend to be the single core structure, where cooperation R\&D between SESs appears.

\section{Situation 2: $M_{1}$ wins}

If $q_{1}-q_{2}>T-S, \lambda^{\prime} \theta_{2}-4 \lambda \theta_{1}<\left(q_{1}-q_{2}+T-S\right) / K \quad, \quad x=1$ is the evolutionary stability strategy and $P_{1}(t)$ wins. To verify the situation, we assignment the related parameters $q_{1}=90, q_{2}=30, \theta_{1}=3, \theta_{2}=0.5$ and then use Matlab to simulate the LV-EG model under three different situation of $x=0.3, x=0.6$ and $x=0.9$, the results are as follows: 


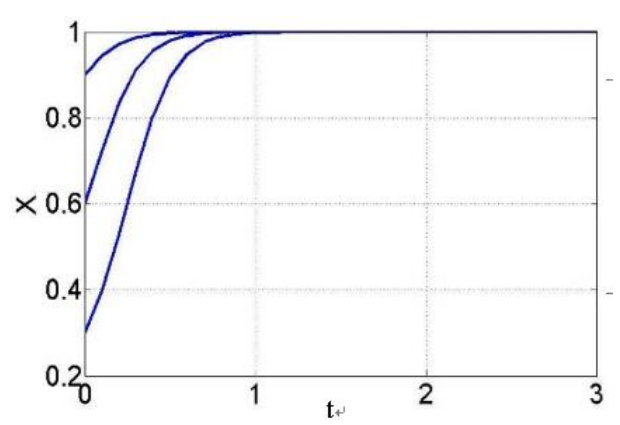

(a) $x$ Evolutionary Trend

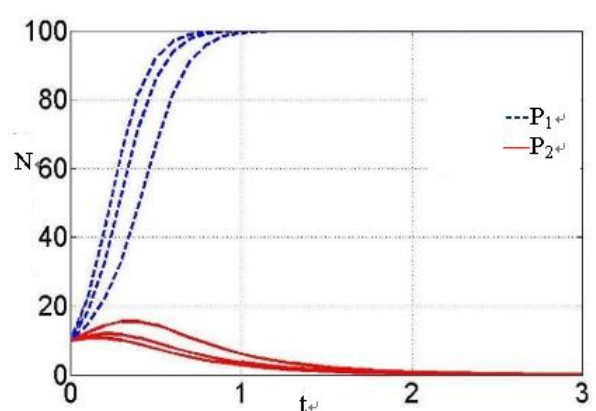

(c) Competition Results

Figure 4. Simulation Results Under $q_{1}=90, q_{2}=30, \theta_{1}=3, \theta_{2}=0.5$

Figure 4 shows that regardless of the initial state of $x$, Although the $m_{1}$ 's production innovation capacity less than $M_{2}$ 's, $M_{1}$ is still able to attract all SES in this cluster network, and gain competitive advantage in the market competition. It is just opposite with situation 1 that SESs belonging to $M_{2}$ tend to change their mind to cooperate with $M_{1}$, and the result is that $M_{1}$ turn to the single core enterprise finally.

\section{Situation 3: $M_{1}$ and $M_{2}$ Coexistence}

If $q_{1}-q_{2}=T-S, \lambda^{\prime} \theta_{2}-4 \lambda \theta_{1}=\left(q_{1}-q_{2}+T-S\right) / K \quad, e$ is the evolutionary stability strategy, At this time the two kinds of productions can be stable coexistence in the longterm competition。To verify the situation, we assignment the related parameters $q_{1}=100, q_{2}=30, \theta_{1}=0.3, \theta_{2}=2.8$ and then use Matlab to simulate the LV-EG model under three different situation of $x=0.3, x=0.6$ and $x=0.9$, the results are as follows:

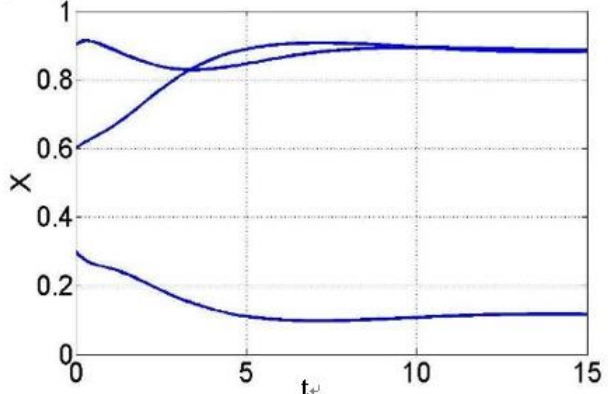

(a) $x$ Evolutionary Trend

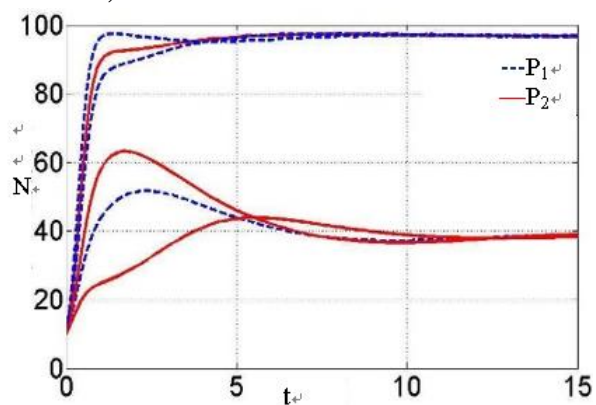

(c) Competition Results

Figure 5. Simulation Results Under $q_{1}=100, q_{2}=30, \theta_{1}=0.3, \theta_{2}=2.8$

Figure 5 shows that $x$ 's initial value has an important impact on $M_{1}$ and $M_{2}$ whose comprehensive strength( $R \& D$ ability and collaborative $R \& D$ ability) is equivalent. If $x=0.6$ or 0.9 , the number of SESs belonging to $M_{1}$ is more than $M_{2}$ 's, while the number of $P_{1}(t)$ is more than $P_{2}(t)$ 's. At this time, the competition intensity and the cooperation intensity will be maintained at a certain level. $M_{1}$, who has a strong independent R \& D ability take the brand product strategy mainly to the production of high tech products, while $M_{2}$ whose independent $\mathrm{R} \& \mathrm{D}$ ability is weak is aimed at the low-end market to avoid the formation of a competitive relationship with $P_{1}(t)$ [18]. The evolution results of the shipping industry cluster network are contrary to the above situation if $x=0.3$. 


\section{Situation 4: $M_{1}$ wins in Situation 1}

With regard to the LV-EG model described above, we do not take the fact that revenue $\lambda$ coming from competitive $\mathrm{R} \& \mathrm{D}$ is different from the revenue $\lambda^{\prime}$ coming from cooperative R\&D into account. But in fact, $\lambda$ and $\lambda^{\prime}$ have an important influence on the competition between shipyards. Through empirical research on the network of the Spanish manufacturing industry, Marchi (2012) has found that a good innovation atmosphere and innovative culture are positively regulating to the interaction between enterprises' cooperation and their R\&D ability [19]. Corresponding to this views, Polidoro (2011), in its research, points out that the stability of the network structure will weaken the impact of competition on their R\&D ability [20]. Therefore, the innovation environment and the stability of the network structure have an influence on $\lambda$ and $\lambda^{\prime}$. Formula (4) indicates that, the inhibition effect $\alpha$ is affected by $\lambda$ and $\lambda^{\prime}$, which can influence the evolution result. We assignment the related parameters which $\lambda_{1}$ and $\lambda_{1}^{\prime}$ is reference to $M_{1}$ while $\lambda_{2}$ and $\lambda_{2}^{\prime}$ is reference to $M_{2}$. Because $\lambda$ and $\lambda^{\prime}$ have changed, the equilibrium conditions of the stable points are changed too, in other words the formula $\lambda^{\prime} \theta_{1}-4 \lambda \theta_{2}<\left(q_{2}-q_{1}+T-S\right) / K$ turn to be like $\left(\lambda_{1}^{\prime}-\lambda_{2}^{\prime}\right) \theta_{1}-4\left(\lambda_{1}-\lambda_{2}\right) \theta_{2}<\left(q_{2}-q_{1}+T-S\right) / K$. To verify the effect of $\lambda$ and $\lambda^{\prime}$ on the simulation results of the model, we take the case 1 as an example, changing the initial state of the model, and observe whether $m_{1}$ and its SESs can win by creating a good innovation environment and building a stable relationship structure. To verify the situation, we assignment the related parameters and then use Matlab to simulate the LV-EG model under three different situation of $x=0.2, x=0.4$, $x=0.6 x=0.8$, the results are as follows:

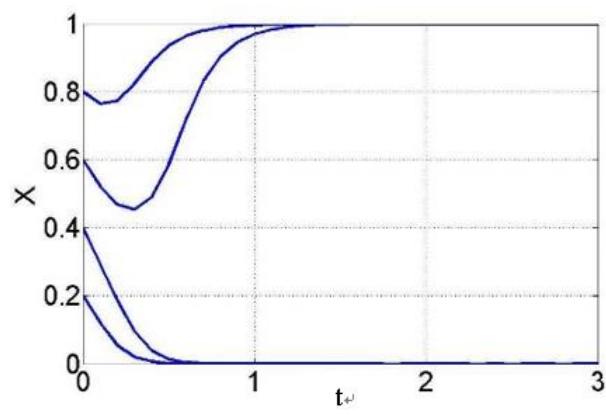

(a) $x$ Evolutionary Trend

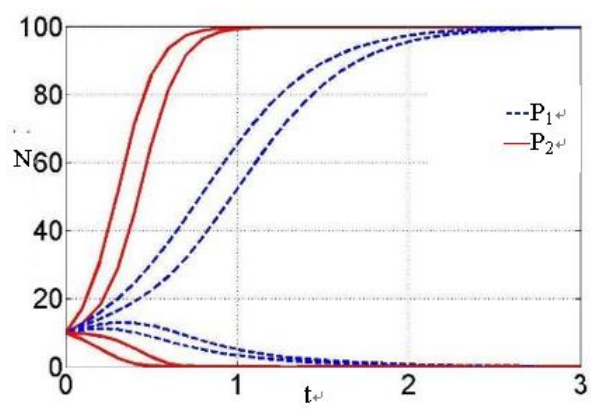

(c) Competition Results

Figure 6. Simulation Results Under

$$
q_{2}=160, q_{1}=80, \theta_{2}=3, \theta_{1}=1, \lambda_{1}^{\prime}=10, \lambda_{2}^{\prime}=1, \lambda_{1}=2, \lambda_{2}=2
$$

Figure 6 shows that $x$ 's initial value has an important impact on the simulation results. The hypothesis "whether $M_{1}$ and its SESs can win by creating a good innovation environment and building a stable relationship structure" is influenced by the initial state of this model. If $x=0.2$ or $x=0.4, M_{1}$ is still unable to attract the subordinate enterprises to join it, and its products will be eliminated in the market competition.

\section{Conclusion}

We firstly construct the multi-level coopetition model of the shipping industry cluster network and secondly use the Lotka-Volterra model and the evolutionary game model to analyze the competitive relationships between shipyards and the coopetition relationships between SESs, and then build the LV-EG model which is used to analyze the mechanism of this process of coopetition among them and their R\&D pattern, and finally use Matlab software to simulate the LV-EG model and get the following conclusions: 
The shipyards who is in a competitive state mainly use the independent $R \& D$ pattern to attract all SESs which adopt joint R\&D pattern in the network, and obtain the advantage in the market competition, while this network forms a single nuclear structure. During this process, the shipyard whose independent $R \& D$ ability is weaker can adopt the collaborative R\&D pattern with SESs, through promoting collaborative R\&D ability with SESs to attract more other SESs to make up for the lack of its independent R\&D ability to come to the fore. The LV-EG model shows that the two different shipyards who are wellmatched in strength can coexist at the same time while the network is relatively stable. Therefore, the key to enhance the competitive advantage of the shipping industry cluster network lies in the combination of independent $R \& D$ pattern, collaborative $R \& D$ pattern and joint $R \& D$ pattern to improve the R\&D ability of the overall network.

The innovation environment and structure of the network have an important influence on the revenue coming from competitive $R \& D$ and cooperative $R \& D$. Based on the Situation1, the equilibrium conditions of the stable point are modified and the LV-EG model is simulated. The results show that the good innovation environment and the stable network structure can positively regulate the promoting effect of cooperation between SESs to their R\&D ability, and enhance the joint R\&D ability, which makes shipyard whose comprehensive ability is weaker can also attract a large number of SESs to obtain the competitive advantage in the long run. Therefore, shipyard should establish a perfect governance mechanism for the shipping industry cluster network with the local government in order to create a good innovation environment and consolidate the stability of the network structure, to build collaborative R\&D platform and optimize the network environment as the way to reduce the cost of different enterprises, and further enhance the international competitiveness of Chinese shipping industry cluster network.

\section{References}

[1] Q. Yin and Y. Xie, "Global shipbuilding market review in 2014 and outlook in 2015", World Shipping, vol. 2, (2015), pp. 24-29

[2] J. Yang and X. Wang, "An empirical study on the key drivers of the evolution of the large complex product manufacturing industry cluster", Research and Development Management, vol. 3, (2011), pp. 25-32.

[3] F. D. C. D Comas and E. B.-Davis, "Eco Innovative Refitting Technologies and Processes for Shipbuilding Industry", Project Overview. Social and Behavioral Sciences, vol. 48, (2012), pp. 37003710 .

[4] S.-fan Chen, "Industrial chain reconstruction of Chinese shipbuilding industry", Chinese ship inspection, vol. 6, (2014), pp. 57-59

[5] J. Park, D. Lee and J. Zhu, "An integrated approach for ship block manufacturing process performance evaluation: Case from a Korean shipbuilding company", International Journal of Production Economics, vol. 156, (2014), pp. 214-222.

[6] K. Wang, G.-M. Zhang and S.-P. Xie, "Research on the characteristics and competitive advantage of the shipbuilding supply chain structure in the shipbuilding industry cluster", Shipbuilding Technology, 1 vol. 33, (2007), pp. 4-6.

[7] J. Yang, "Research on the organization mode of supply chain system for complex product manufacturing industry cluster", Scientific Research Management, vol. 1, (2011), pp. 153-160.

[8] I. Ruuska, T. Ahola and M Martinsuo, "Supplier capabilities in large shipbuilding projects", International Journal of Project Management, vol. 31, no. 4, (2013), pp. 542-553.

[9] H. Choi, S. Kim and J. Lee, "Role of network structure and network effects in diffusion of innovations", Industrial Marketing Management, vol. 39, no. 1, (2010), pp. 170-177.

[10] R. Levering, R. Ligthart and N. Noorderhaven, "Continuity and change in interorganizational project practices: The Dutch shipbuilding industry", 1950-2010. International Journal of Project Management, vol. 31, no. 5, (2013), pp. 735-747.

[11] P. Norback, L. Persson and J. Tag, "Acquisitions, entry, and innovation in oligopolistic network industries", International Journal of Industrial Organization, 37, (2014), pp. 1-12.

[12] A. Xu and Y.Long, "Research on the effect of product competition and technology cooperation-The empirical analysis of the evolution of the user's competition based on China Mobile and China Unicom", Soft Science in China, vol. 1, (2008), pp. 116-124. 
[13] Y. Chen and F. Xie, "Study on bionic evolutionary path of photovoltaic industry ecological innovation system based on Lotka-Voterra model", Research and Development Management, vol. 3, (2012), pp. 7484.

[14] A. Nagurney, M. Yu and J. Floden, "Supply chain network sustainability under competition and frequencies of activities from production to distribution", Computational Management Science, vol. 10, no. 4, (2013), pp. 397-422.

[15] E. I. Malecki, "Network models for technology-based growth", Regional Innovation And Global, (2013), pp. 187-227.

[16] C. Watts and N. Gilbert, "Simulating Innovation: Comparing Models of Collective Knowledge", Technological Evolution and Emergent Innovation Networks, Advances in Social Simulation, Springer Berlin Heidelberg, (2014), pp. 189-200.

[17] D. Friedman, "Evolutionary games in economics", Econometrica, vol. 59, no. 1, (1991), pp. 637-6660.

[18] A. Grubler, L. D. Anadón and K. S. Gallagher, "21 Global R\&D, Market Formation, and Diffusion Investments in Energy Technology Innovation”, Energy Technology Innovation, (2014), pp. 292-301.

[19] D. V. Marchi, "Environmental innovation and R\&D cooperation: Empirical evidence from Spanish manufacturing firms", Research Policy, vol. 41, no. 3, (2012), pp. 614-623.

[20] F. Polidoro, G. Ahuja and W. Mitchell, "When the social structure overshadows competitive incentives: The effects of network embeddedness on joint venture dissolution", Academy of Management Journal, vol. 54, no. 1, (2011), pp. 203-223.

\section{Authors}

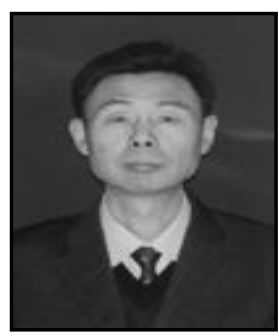

Zhao Jinlou, (1957- ), male, born in Cangzhou Hebei, PHD, Doctoral tutor, Director of the institute of economic management of marine industry, Harbin Engineering University, Research direction for the shipbuilding industry management.

Ge Gang, (1972- ), male, born in Harbin Heilongjiang, Doctoral student, Research direction for the shipbuilding industry management. Tel: 18810258959, Email:luciferyao@126.com. 